\title{
A INTERNACIONALIZAÇÃO A PARTIR DE DIFERENTES LOCI DE ENUNCIAÇÃO: AS CONCEPÇÕES DE SUJEITOS PRATICANTES DO CURRÍCULO PROFISSIONAL
}

\section{INTERNATIONALIZATION FROM DIFFERENT LOCI OF ENUNCIATION: CONCEPTS BY THE PROFESSIONAL CURRICULUM PRACTITIONERS}

\section{Gabriela Freire Oliveira Piccin* Kyria Rebeca Finardi ${ }^{* *}$}

\section{RESUMO}

A internacionalização da educação tem recebido diferentes definições e abordagens entre os países, instituições de ensino superior (IES) e demais agentes (KNIGHT, 2003; 2004). Alguns autores, entretanto, têm identificado certos "equívocos" (DE WIT, 2011) e "mitos" (KNIGHT, 2011) quanto às concepções que perpassam a ideia de internacionalização da educação, apontando possíveis riscos e consequências indesejáveis desse processo. Por essa razão, torna-se urgente discutir criticamente as diferentes definições que a internacionalização pode assumir (AZEVEDO, 2014), em especial as perspectivas dos sujeitos praticantes (CERTEAU, 2009) do currículo, objetivo principal deste estudo. A presente pesquisa buscou trazer as concepções de atores sociais do processo de internacionalização das IES, a saber, os servidores da Rede Federal de Educação Profissional, Científica e Tecnológica (RFEPCT), acerca do conceito de internacionalização, em diálogo com as concepções de estudiosos da área. Para tanto, um questionário semiestruturado foi aplicado a servidores da RFEPCT com diferentes cargos e funções, representando, na medida do possível, as cinco regiões geográficas do Brasil. O estudo também contou com uma revisão de literatura dos principais modelos teóricos desenvolvidos e do debate sobre o processo de internacionalização das IES a partir de uma base crítica. Os dados oriundos dos questionários foram analisados qualitativamente, e a discussão é apresentada em diálogo com os estudos sobre internacionalização.

Palavras-chave: Internacionalização da educação; sentidos produzidos por sujeitos praticantes do currículo; Rede Federal de Educação Profissional, Científica e Tecnológica.

\section{ABSTRACT}

The internationalization of education has received different definitions and approaches among countries, higher education institutions (HEIs) and other agents (KNIGHT,

\footnotetext{
* Instituto Federal do Espírito Santo (IFES), Vitória, ES, Brasil. gfopiccin@gmail.com

** Universidade Federal do Espírito Santo (UFES), Vitória, ES, Brasil. kyria.finardi@gmail.com
} 
2003; 2004). Some authors, however, have identified certain "misconceptions" (DE WIT, 2011) and "myths" (KNIGHT, 2011) regarding the concepts that permeate the idea of internationalization of education, and they point out possible risks and undesirable consequences of this process. For this reason, it is in urgent need to critically discuss the different definitions that internationalization might receive (AZEVEDO, 2014), especially the perspectives of the practitioner subjects (CERTEAU, 2009) of the curriculum, which is the main objective of this study. The present research attempted to investigate the concepts of internationalization negotiated by social actors of the internationalization process in HEIs, namely the public servers of the Brazilian Federal Network of Professional, Scientific and Technological Education (RFEPCT). Furthermore, the study brings these interpretations in dialogue with those by academics from the area. For this purpose, a semistructured questionnaire was applied to RFEPCT public servers with different positions and functions, representing, as far as possible, the five geographic regions of Brazil. The study also had a literature review of the main theoretical models, as well as of the debate about the internationalization process of HEIs from a critical base. The data from the questionnaires were analyzed qualitatively, and the discussion is presented in dialogue with the studies on internationalization.

Keywords: Internationalization of education; Meanings produced by curriculum practitioners; Brazilian Federal Network of Professional, Scientific and Technological Education.

\section{INTRODUÇÃO}

A internacionalização das instituições de ensino superior (IES) tem recebido cada vez mais destaque nas agendas de diversos países, tornando-se um termo recorrente nos discursos que permeiam as políticas públicas nos setores da educação e da ciência e tecnologia (FORTES, 2016), além de objeto de análise de estudiosos de áreas como a Educação e as Ciências Sociais (por exemplo, KNIGHT, 2003; SOUSA SANTOS, 2011; FINARDI et al., 2016; FORTES, 2016; OLIVEIRA, 2018). Ainda que a internacionalização do ensino superior esteja presente desde as origens das universidades modernas na Idade Média (LAUS, 2012; ALTBACH, 2016), o fenômeno da internacionalização contemporânea é bastante recente. Knight (2003) relata que o termo internacionalização tem sido utilizado há séculos nas ciências políticas e nos discursos que permeiam as relações governamentais, mas que seu uso objetivo no campo da Educação se consolidou nos anos 1980, atingindo maior destaque na área a partir da década de 1990. Entretanto, no contexto brasileiro, Lima e Maranhão (2009) apontam que, de modo geral, o tema não recebeu tanta atenção nas pesquisas, divergindo assim das tendências internacionais, e Finardi e Archanjo (2018) afirmam que foi só depois do advento do programa Ciências sem Fronteiras (CsF) que a internacionalização entrou na pauta da maior parte das universidades brasileiras. 
A fim de preencher algumas dessas lacunas quanto à pesquisa sobre a internacionalização das IES brasileiras, o presente estudo tem por objetivo investigar as concepções de internacionalização que os sujeitos praticantes ${ }^{1}$ (CERTEAU, 2009) do currículo ${ }^{2}$ negociam, traçando diálogos entre esses com os conceitos propostos por teóricos da área. Busca-se, assim, analisar criticamente os sentidos produzidos pelos sujeitos participantes deste estudo, levando-se em consideração (1) os apontamentos de Knight (2011) e de Wit (2011) acerca de possíveis interpretações equivocadas e mitos sobre a internacionalização, e seus potenciais riscos e consequências; e (2) a discussão sobre os efeitos da visão da educação como commodity que tem se sobreposto aos sentidos tradicionais de internacionalização do ensino superior. Assim sendo, este estudo traz as definições de internacionalização propostas por atores sociais envolvidos no processo de internacionalização das IES, a saber os servidores da Rede Federal de Educação Profissional, Científica e Tecnológica (RFEPCT), em diálogo com a literatura da área.

\section{MODELOS CONCEITUAIS E DISCUSSÕES TEÓRICAS SOBRE A INTERNACIO- NALIZAÇÃO DO ENSINO SUPERIOR}

A fim de enlaçar os conceitos de internacionalização do ensino superior mais adotados pela literatura acadêmica com a discussão crítica do processo mundial de internacionalização das IES, esta seção foi dividida em duas subseções. Na primeira apresentamos o que internacionalização é e o que ela não é, a partir, principalmente, das contribuições de Knight $(1994 ; 2003 ;$ 2004; 2011; 2012) e de Wit (2011). $\mathrm{Na}$ segunda subseção são apresentadas as discussões que questionam o modelo hegemônico de internacionalização da educação pautado no ideário neoliberal, e que tem sido implementado pela maioria das IES.

1. Segundo Michel de Certeau (2009), sujeitos praticantes são aqueles que praticam a realidade, ou seja, que inventam e produzem novos usos, significações e conhecimentos cotidianamente. Este estudo buscou investigar os sentidos de internacionalização negociados pelos sujeitos praticantes dos currículos da Rede Federal de Educação Profissional, Científica e Tecnológica (RFEPCT), a saber os servidores da RFEPCT

2. Por "currículo" não compreendemos apenas os documentos governamentais ou institucionais que descrevem os objetivos, planos, temas e conteúdos, mas também as experiências concretas desenvolvidas na interação entre os sujeitos da escola (SACRISTÁN, 1995), isto é, os currículos realizados (FERRAÇO, 2013) pelos sujeitos praticantes (CERTEAU, 2009). 


\subsection{Desenvolvendo o conceito de internacionalização: importantes pistas teóricas a partir das contribuições de Jane Knight e Hans de Wit}

Uma questão bastante relevante quanto à definição da internacionalização da educação refere-se à sua relação com a globalização. Knight (2004) aponta certa dificuldade para se diferenciar os dois fenômenos uma vez que ambos estão intimamente interligados. Segundo a autora, a "internacionalização está mudando o mundo da educação superior, ao passo que a globalização está mudando o mundo da internacionalização" (KNIGHT, 2004, p. 5, tradução nossa ${ }^{3}$ ). Assim, Knight (2012) esclarece que, enquanto a globalização remete ao fluxo global de ideias, conhecimentos, pessoas, bens, serviços e tecnologias, a internacionalização, por sua vez, evidencia as relações entre os países, povos, culturas e instituições.

Dito isso, cabe destacar ainda que as definições de internacionalização podem divergir não apenas entre países, mas também entre as IES no interior de um mesmo país (KNIGHT, 2004) ou ainda entre os agentes envolvidos dentro de uma determinada comunidade acadêmica (vide AMORIM; FINARDI, 2017). De acordo com Knight (2004), isso acontece por causa dos diferentes contextos das realidades que temos hoje, o que implica novos desafios para o desenvolvimento de um modelo conceitual capaz de esclarecer os significados e princípios da internacionalização, a fim de orientar suas políticas e práticas. Isso não quer dizer, entretanto, que seja necessário se desenvolver uma definição universal, mas é preciso que se trabalhe com um modelo conceitual que seja "apropriado para usar em uma ampla gama de contextos e para fins comparativos entre países e regiões do mundo" (KNIGHT, 2004, p. 10, tradução nossa4).

Dessa forma, Knight (2003) desenvolve um modelo conceitual de internacionalização bastante adotado por teóricos e estudiosos da internacionalização da educação. Para a autora, a internacionalização seria o processo de integração das dimensões internacional, intercultural ou global, seja nos objetivos, funções ou na oferta do ensino superior (KNIGHT, 2003). Antes disso, Knight (1994) já havia apresentado a definição de internacionalização enquanto um processo que integrava a dimensão internacional ao ensino/aprendizagem, à pesquisa e demais missões da universidade. Por "dimensão internacional", Knight (1994) se referia

3. No original: "Internationalization is changing the world of higher education, and globalization is changing the world of internationalization" (KNIGHT, 2004, p. 5).

4. No original: "Although it is not necessarily the intention to develop a universal definition, it is imperative that it be appropriate for use in a broad range of contexts and for comparative purposes across countries and regions of the world" (KNIGHT, 2004, p. 10). 
às atividades, perspectivas e aos serviços que introduziam aspectos internacionais, interculturais e/ou globais às principais funções e objetivos da educação superior. Apesar dessa definição anterior compreender a internacionalização como processo e não como atividade com um fim em si mesma, é bastante comum a compreensão de internacionalização enquanto atividades ou instrumentos com algum teor internacional (KNIGHT, 2004; DE WIT, 2011), o que pode resultar em certos riscos e possíveis consequências indesejáveis para o processo de internacionalização das IES.

Em face disso, de Wit (2011) argumenta que a internacionalização parece ter se tornado o conjunto de estratégias para promover a si mesma, transformandose nos meios para alcançar a si mesma, esquecendo, assim, de sua finalidade. Nesse sentido, o autor apresenta nove "conceitos equivocados", frequentemente considerados sinônimos de internacionalização, a saber: (1) oferecer disciplinas ministradas em língua inglesa, (2) estudar ou morar em um país estrangeiro, (3) ofertar disciplinas com conteúdo ou conotação internacional, (4) ter grande número de alunos estrangeiros matriculados na instituição, (5) ter a presença de alguns estudantes estrangeiros na instituição, (6) dispensar a avaliação das competências internacionais e interculturais por acreditar que elas serão naturalmente adquiridas através de atividades de teor internacional, (7) quanto maior a quantidade de parcerias, mais internacionalizada a instituição será, (8) a educação superior é por natureza internacionalizada, e, por fim, (9) a internacionalização é um fim em si mesmo (DE WIT, 2011). Após definir o que a internacionalização não é, o autor estabelece a sua compreensão do conceito, que dialoga bastante com a concepção proposta por Knight (2003): "um processo para introduzir as dimensões intercultural, internacional e global ao ensino superior, a fim de melhorar seus objetivos, funções e a oferta do ensino superior; aperfeiçoando a qualidade da educação e da pesquisa" (DE WIT, 2011, p. 6, tradução nossa ${ }^{5}$ ). Nessa definição fica claro quais são os objetivos da internacionalização e o fato de que ela é um meio para alcançar esses objetivos.

Assim como De Wit (2011), Knight (2011) aponta cinco "mitos" semelhantes aos conceitos equivocados, que, segundo ela, são resultantes da crença de que tudo aquilo que pode configurar uma remota conexão com aspectos globais, interculturais ou internacionais trata-se de internacionalização da educação. Os mitos identificados por Knight (2011) são: (1) que estudantes estrangeiros são

5. No original: "Internationalization is a process to introduce intercultural, international, and global dimensions in higher education; to improve the goals, functions, and delivery of higher education; and thus to upgrade the quality of education and research" (DE WIT, 2011, p. 6). 
agentes da internacionalização, (2) que a reputação internacional é certificado de qualidade, (3) que quanto mais parcerias, convênios e acordos internacionais uma universidade firma, mais atraente e atrativa ela se torna para o público discente e para outras IES, (4) que quanto maior o reconhecimento de qualidade conferido por agências e órgãos internacionais, mais internacionalizada é a instituição, e (5) que o propósito de uma instituição se internacionalizar é de melhorar sua "marca". Knight (2011) salienta que nem todos os países e/ou IES expressam esses mitos sobre a internacionalização, mas que tais crenças requerem reflexão, ainda mais quando a competição, os rankings e o comércio da educação superior parecem orientar cada vez mais as políticas e práticas de internacionalização.

Após identificar essas cinco concepções equivocadas, Knight (2012) delineia cinco verdades acerca da internacionalização. A primeira delas tem a ver com o respeito às questões locais, ou seja, de que a dimensão internacional não deve se sobrepor ao contexto local. Knight (2012) adverte que não observar essa verdade pode conferir um caráter homogeneizante ou hegemônico à internacionalização.

Em relação a esse risco homogeneizante e hegemonizante da internacionalização, Semeraro (2012), no mesmo ano da publicação de Knight (2012), mas tratando de outro tema e abordando a questão da hegemonia pelo viés dos movimentos sociais no Brasil, fala da busca pela identidade brasileira que segundo o autor está, não por acaso, ligada ao movimento de Libertação na medida em que denuncia o modelo arbitrário de sociedade opressiva que nos foi imposto "de fora e pelo alto" (SEMERARO, 2012, p. 32) e que se seguiu à ditadura reprimindo organizações políticas, mobilizações estudantis, sindicatos e outros movimentos sociais. Nesse sentido, o movimento de Libertação não foi uma simples reação à ditadura mas se rebelava contra todas as formas de opressão nas versões "Casa grande e senzala" (SEMERARO, 2012, p. 32) que tiveram diversas formas no Brasil desde as capitanias hereditárias até as corporações transnacionais e nós podemos acrescentar, atualmente, à internacionalização da educação.

Nesse sentido e conforme já alertado por Finardi e Guimarães (2017) sobre o modelo de internacionalização "importado" "de fora e pelo alto" que adotamos no Brasil, nos perguntamos até que ponto esse modelo é local e nos propicia uma educação emancipadora que lute contra as diversas formas de dominação disseminadas por modelos "globais" hegemônicos.

Voltando aos movimentos de Libertação e de Hegemonia analisados por Semeraro (2012), a convergência das aspirações desses dois movimentos no Brasil mostrou como o Terceiro Mundo é resultado da violência praticada pelo ocidente e não o resultado da inferioridade inerente de seus habitantes "dependentes". A 
situação de dependência não poderia mesmo ser superada pela simples "imitação" dos modelos dominadores, como denunciado por Finardi e Guimarães (2017) no tocante ao modelo de internacionalização adotado no Brasil. Segundo a ideologia marxista esposada na visão de hegemonia descrita em Semeraro (2012), a pobreza do Terceiro Mundo é resultado da riqueza dos países centrais (ou do Norte Global na visão de Sousa Santos, $2011^{6}$ ), sendo que o modelo "desenvolvimentista" do ocidente/norte nada mais faz além de aprofundar e reproduzir desigualdades.

Essas reflexões levaram o mundo a reconhecer as mazelas do Terceiro Mundo para além da visão marxista de patrão-operário ou da linha Leste-Oeste para outro grande eixo/brecha que se formava na direção Norte-Sul e que foram depois denunciadas, no contexto da internacionalização da educação, por pensadores tanto do Norte Global (vide VAVRUS, PEKOL, 2015) quanto do Sul (vide SOUSA SANTOS, 2011). Agora já não eram três mundos, mas dois, o mundo dos países centrais (ou do Norte Global) e o mundo dos países do Sul, os periféricos ou "esfarrapados" para usar o termo que Freire adota em Pedagogia do Oprimido (FREIRE, 1970).

A segunda verdade acerca da internacionalização segundo Knight (2012) se pauta no conceito apresentado anteriormente pela autora (KNIGHT, 2003) de que a internacionalização é um processo que conduz "à integração da dimensão internacional, intercultural e global às metas, funções e implementação do ensino superior" (KNIGHT, 2012, p. 64), sendo, portanto, adaptável e suscetível a mudanças, de acordo com os interesses e demandas de cada instituição.

Segundo a autora (2012), a terceira verdade diz respeito aos benefícios, riscos e consequências não intencionais da internacionalização. A autora ilustra essa categoria com o caso do enfoque nos benefícios que, por exemplo, a mobilidade acadêmica pode trazer sem se considerar os riscos decorrentes da mobilidade, como o fenômeno de "fuga de cérebros"7 (brain drain), ou ainda os riscos que uma universidade assume ao depender demasiadamente de fundos provenientes de taxas pagas por estudantes estrangeiros, o que pode levar à precarização dos critérios de qualidade da instituição, impulsionando o comércio de títulos, colocando, mais uma vez, a educação como mercadoria (commodity).

A quarta verdade apontada por Knight (2012) dialoga diretamente com o último "conceito equivocado" apresentado por de Wit (2011), ou seja, a autora reafirma que a internacionalização não é um fim em si mesmo. Esse é um

6. Os termos "Norte" e "Sul" neste artigo são utilizados conforme Sousa Santos (2011) que se refere ao Norte e Sul epistemológicos, e não necessariamente geográficos.

7. Fenômeno que se refere ao fato de países ricos atraírem pesquisadores de países mais pobres. 
ponto importante para a discussão proposta neste artigo uma vez que Knight (2012) destaca os principais objetivos de se internacionalizar as IES, como o de desenvolver as competências, habilidades e conhecimentos interculturais dos estudantes, preparando-os para viver em um mundo mais interconectado, ao invés da simples obtenção de um currículo dito mais internacional ou o aumento das taxas de mobilidade acadêmica. Compreender a internacionalização enquanto processo significa percebê-la como um meio para se atingir um fim e não uma finalidade em si mesma.

A quinta verdade, por sua vez, retoma as importantes distinções entre globalização e internacionalização anteriormente mencionadas, mas também suas imbricadas relações positivas e negativas. A globalização influenciou, por exemplo, o estabelecimento da educação transfronteiriça ${ }^{8}$. Por outro lado, Knight (2012) observa que a internacionalização, antes percebida como um processo baseado em cooperação e solidariedade para a construção e difusão do conhecimento, agora é cada vez mais vista como forma de mercantilização da educação devido aos efeitos negativos da globalização já apontados por Vavrus e Pekol (2015) e citados por Finardi, Santos e Guimarães (2016).

Azevedo (2014) reconhece a importância das contribuições de Knight (2011; 2012) e de Wit (2011) acerca dos mitos e equívocos, bem como das verdades em torno da concepção de internacionalização para o desenvolvimento de uma reflexão crítica. Desse modo, Azevedo (2014) ressalta a necessidade de se questionar quaisquer verdades fundamentais na academia, por isso as pistas teóricas traçadas por de Wit (2011) e Knight $(2011$; 2012) podem nos auxiliar a interrogar certos enunciados recorrentes nas políticas e práticas que visam internacionalizar as IES. A partir de tais pistas teóricas, Azevedo (2014) conclui que para além da compreensão de Knight (2003) quanto à integração das dimensões internacional, intercultural e global às funções e aos objetivos das IES, há interpretações que se distanciam desse caráter humanístico e solidário, potencializando a competição e o viés capitalista e mercantil que a internacionalização pode assumir.

8. A educação transfronteiriça é um dos quatro modos de oferta transnacional de serviços universitários descritos pelo Acordo Geral sobre o Comércio de Serviços (GATS) e que serão discutidos no decorrer do texto. Segundo Sousa Santos (2011, p. 34-35, grifos do autor), o modo de oferta transfronteiriça "consiste na provisão transnacional do serviço sem que haja movimento físico do consumidor. Nela se incluem educação à distância, aprendizagem on line [sic], universidades virtuais. É por enquanto um mercado pequeno mas com forte potencial de crescimento. Um quarto dos estudantes que seguem, a partir do estrangeiro, cursos em universidades australianas fá-lo pela Internet. Três grandes universidades norte-americanas (Columbia, Stanford e Chicago) e uma inglesa (London School of Economics) formaram um consórcio para criar a Cardean University que oferece cursos no mundo inteiro pela Internet". 


\subsection{Desenvolvendo concepções críticas sobre a internacionalização}

Conforme os apontamentos de Knight (2012), observa-se um deslocamento da perspectiva da internacionalização da educação enquanto um meio de trocas e colaboração entre universidades de diferentes nações, para uma concepção de caráter mais comercial e competitivo. Prova disso é o estímulo ao comércio internacional da educação que a Organização Mundial do Comércio (OMC) tem promovido, a fim de atender às diretrizes do Acordo Geral sobre o Comércio de Serviços (GATS) ${ }^{9}$. Os países membros da OMC que aderem ao GATS são contemplados com maiores facilidades referentes à mobilidade acadêmica por meio da (1) oferta transfronteiriça, (2) do consumo no estrangeiro, (3) da presença comercial e (4) da presença de pessoas $\left(\mathrm{ALTBACH}_{i} \mathrm{KNIGHT}\right.$ 2007). Segundo Altbach e Knight (2007), o primeiro meio de oferta de serviços universitários previstos pelo GATS, a oferta transfronteiriça, pode incluir a modalidade de ensino a distância, além de cursos de franquias ou níveis, não se exigindo, portanto, a presença física do sujeito. Já o meio "consumo no exterior" refere-se ao deslocamento físico desse sujeito "consumidor" para o país provedor. No terceiro meio, a presença comercial, o provedor privado firma filiais em outros países. Por último, a "presença de pessoas" se remete ao fluxo de docentes e pesquisadores que se deslocam temporariamente para outro país a fim de prestar algum serviço educacional.

Sousa Santos (2011) ressalta o viés mercadológico da educação presente em cada um desses modos e que tem acentuado cada vez mais o desequilíbrio de forças entre os países do Norte e do Sul. Nesse sentido, Andreotti et al.(2016) refletem sobre o imaginário coletivo que pode também estar contribuindo na intensificação das desigualdades entre esses países. Com base em dados obtidos do programa Ciências Sem Fronteiras (CsF) acerca das perspectivas de sujeitos que se deslocam do Sul para estudar no Norte, Andreotti et al.(2016) observam que esses estudantes acreditam que a mobilidade acadêmica possibilitará que eles adquiram um suposto "conhecimento universal" com o qual retornarão para o Sul, podendo assim contribuir no futuro com seu país de origem. Em contraposição a essa perspectiva, Andreotti et al. (2016) identificam, em alguns estudos sobre mobilidade internacional, uma das principais motivações de estudantes do Norte que se deslocam para o Sul: colaborar com o desenvolvimento do país do Sul para o qual se dirigem. Em outras palavras, enquanto os estudantes dos países ditos periféricos presumem que a mobilidade acadêmica lhes permitirá "consumir" um suposto "conhecimento universal" que pertenceria aos países centrais, os estudantes

9. No original em inglês: General Agreement on Trade in Services (GATS). 
do Norte, por sua vez, têm uma visão salvacionista e colonizadora em relação ao Sul: percebem sua participação em programas de mobilidade para aqueles países como oportunidade de ajudá-los em seu desenvolvimento, talvez por levarem consigo esse "conhecimento universal" que lhes é próprio.

A fim de elucidar as desigualdades entre os países nessas relações de mobilidade acadêmica universitária, Lima e Maranhão (2009) desenvolvem os conceitos de internacionalização ativa e passiva onde países com internacionalização ativa atraem acadêmicos estrangeiros enquanto os países com internacionalização passiva enviam mais acadêmicos do que recebem. As autoras percebem essas disparidades na forma que a mobilidade acadêmica se manifesta através dos quatro modelos propostos pelo GATS, mencionados acima na discussão teórica de Altbach e Knight (2007) e Sousa Santos (2011). Para Lima e Maranhão (2009),

\begin{abstract}
enquanto a inserção internacional do setor educacional, existente nos países centrais, se manifesta de forma ativa, isto é, com a implantação de políticas de Estado voltadas para a atração e acolhimento de acadêmicos, a oferta de serviços educacionais no exterior envolvendo a mobilidade de experts em áreas de interesse estratégico, a exportação de programas e instalação de instituições ou campi no exterior; nos países periféricos ela se manifesta de forma diferente [passiva]: observa-se a necessidade de definir criteriosa política de emissão de acadêmicos (principalmente professores-pesquisadores) para se formar nos grandes centros, objetivando investirno desenvolvimento de uma elite intelectual capaz de influir sobre o processo de modernização de alguns setores [...] (2009, p. 586, grifos das autoras).
\end{abstract}

Com base em dados advindos de pesquisas na área, Lima e Maranhão (2009) ressaltam que as motivações de estudantes de países com internacionalização de tipo passiva para participar de programas de mobilidade acadêmica são, em muitos casos, de fundo econômico. Assim, as autoras argumentam quanto aos riscos de tal motivação, especialmente quanto ao fenômeno de brain drain, ou seja, o fator econômico impulsionar a saída de potenciais capitais humanos dos países de internacionalização do tipo passiva para os de tipo ativa, sendo que geralmente os primeiros são oriundos do Sul e os últimos do Norte. Considerando o enfoque no lucro de muitos desses programas de mobilidade acadêmica para universidades do Norte (SOUSA SANTOS, 2011), podemos inferir que as possíveis consequências de tais acordos não dizem respeito apenas à "fuga de cérebros", mas também de recursos materiais e fundos visto que os governos e/ou estudantes do Sul tendem a investir valores significativos em cursos ofertados por essas universidades do Norte.

Outro ponto que beneficia mais os países ditos centrais (os do Norte global) refere-se aos novos agentes interessados na internacionalização da educação que geralmente estão localizados nesses países. Segundo Knight (2004), esses novos 
atores têm participado ativamente tanto de atividades de caráter doméstico quanto internacional. De acordo com a autora, esses agentes podem ser

empresas de mídia como Pearson (Reino Unido) e Thomson (Canadá); multinacionais como a Apollo (Estados Unidos, proprietária das Universidades Phoenix), a Informatics (Cingapura), a Slyvan (Estados Unidos) e a Aptech (Índia); universidades corporativas; e redes de associações e organizações profissionais. Geralmente, esses novos fornecedores comerciais estão ocupados principalmente com o ensino / treinamento ou a prestação de serviços e não focam no desenvolvimento da pesquisa em si. Eles podem complementar, cooperar ou competir com instituições de ensino superior públicas e privadas cuja missão está tradicionalmente na tríade de ensino, pesquisa e extensão (KNIGHT, 2004, p. 7, tradução nossa $\left.{ }^{10}\right)$.

Nesse sentido, Fortes (2016) traz as discussões e os questionamentos acerca das consequências que a atuação desses atores identificados por Knight (2004) têm gerado para governos, instituições de ensino superior, estudantes e pesquisadores. Fortes (2016) alerta, assim, a transferência de fundos públicos para o setor privado através do pagamento de serviços de editoração, indexação, classificação e ranking prestados por grandes grupos e multinacionais que têm dominado esses ramos do "mercado" da educação superior internacional. $\mathrm{O}$ autor avalia que volumosas quantias de recursos públicos destinados ao desenvolvimento da ciência brasileira são direcionados para esses grupos e empresas, "seja para inclusão das revistas nas bases de editoração e/ou de indexação, seja pela assinatura destas bases para que os artigos sejam acessados pelos pesquisadores e estudantes brasileiros" (FORTES, 2016, p. 181). O autor também argumenta que tal negócio milionário não tem pago seus "trabalhadores": há movimentos, especialmente de pesquisadores e cientistas do Norte, que reivindicam a remuneração pelo serviço que prestam como pareceristas, o que, segundo Fortes (2016), causa certo estranhamento para alguns acadêmicos brasileiros que ainda se colocam em posição de subalternidade e oferecem os mesmos serviços gratuitamente sem maiores questionamentos. Como possíveis alternativas para conter a transferência de capital público para o privado, o autor sugere que parte desses recursos públicos seja destinada para a difusão do conhecimento através de duas medidas, a saber

10. No original: "media companies such as Pearson (United Kingdom) and Thomson (Canada), multinational companies such as Apollo (United States, which owns Phoenix Universities), Informatics (Singapore), Slyvan (United States), and Aptech (India); corporate universities; and networks of professional associations and organizations. Generally, these new commercial providers are mainly occupied with teaching/ training or providing services and do not focus on research per se. They can complement, cooperate, or compete with public and private higher education institutions whose mandate is traditionally the trinity of teaching, research, and service" (KNIGHT, 2004, p. 7). 
a) investir nas revistas brasileiras, através da remuneração (por intermédio de bolsas e/ou de pagamentos avulsos) aos que nelas trabalham: editores, assistentes, pareceristas, tradutores etc.; b) investir em traduções, para o português, de trabalhos (artigos e livros) relevantes publicados em outros idiomas (FORTES, 2016, p. 182).

Dessa forma, ao invés de se desvalorizar a produção acadêmica brasileira, que segundo Finardi e França (2016) é robusta ${ }^{11}$, se estimularia o desenvolvimento da editoração científica nacional e sua divulgação, freando a transferência de fundos públicos para corporações e multinacionais. O investimento em traduções, citado na primeira medida, beneficiaria a circulação de nossa produção internacionalmente fazendo com que ela tivesse maior impacto na ciência mundial uma vez que para ser citado é preciso ser lido, conforme apontado por Finardi e França (2016). A segunda medida sugerida por Fortes (2016), referente às políticas linguísticas, também reivindica a democratização do conhecimento através da tradução para a língua portuguesa de publicações científicas em outros idiomas, para que seu acesso esteja livre e disponível para a comunidade acadêmica e a sociedade em geral. Ambas as medidas sugeridas por Fortes (2016) são relevantes para que o Brasil desenvolva uma política de internacionalização ativa, conforme Lima e Maranhão (2009), fortalecendo a produção do conhecimento e sua democratização.

Para além da atuação desses novos atores, Leite e Genro (2012) advertem que é preciso que se atente para a nova epistemologia que rege a educação superior, bem como sua neolíngua bastante aceita e repetida tanto pelos discursos ditos oficiais quanto pelos sujeitos que habitam as IES da América Latina e do Caribe. Termos como qualidade, avaliação, reconhecimento internacional, credenciamento e rankings das IES foram assimilados e naturalizados nos contextos das universidades latinas e caribenhas sem muita reflexão. As autoras ressaltam os riscos do reconhecimento e da aceitação acrítica por parte dos países do Sul dessa nova epistemologia pautada no ideário neoliberal: a de um novo imperialismo que homogeneíza os currículos, desconsiderando e deslegitimando os aspectos, as relações e os conhecimentos locais, além de submeter os governos, as IES e os acadêmicos do Sul a padrões e critérios de avaliação produzidos pelos países do Norte - conforme já alertado por Finardi e Guimarães (2017) -, a fim de atender os interesses desses últimos por meio da dominação hegemônica. Para esse novo imperialismo, a educação tem um papel central:

A Educação Superior teria um papel estratégico na efetivação deste imperialismo europeu sutil. A dimensão ideacional do Processo de Bolonha poderia estar a infiltrar, dentro do possível, processos de coerção na constituição de agendas políticas. A nova dinâmica estaria

11. Segundo esses autores, a produção acadêmica nacional em 2016 era a $13^{\mathrm{a}}$ maior do mundo. 
baseada na persuasão e na sedução dos sujeitos sujeitados, atuantes em diferentes instituições de Ensino Superior (IES). Influiria, inclusive, nas políticas de Estado (LEITE; GENRO, 2012, p. 770-771, grifos nossos).

Tal influência nas políticas governamentais estaria embasada na própria ideologia neoliberal que advoga em defesa do Estado mínimo ${ }^{12}$. Leite e Genro (2012) notam que, se por um lado há o forte discurso contra os atores públicos em prol do setor privado, por outro se observam estratégias para angariar os recursos públicos: a avaliação e a acreditação conferidas por agências internacionais globais às IES de países da América Latina e do Caribe são utilizadas como moedas de negociação com organismos como o Banco Mundial (BM).

Segundo Leite e Genro (2012), são diversas as agências globais que avaliam a educação superior latina, destacando-se a atuação da União Europeia (EU) e a consolidação da área comum de educação superior, ALCUE ou UEALC, bem como o papel desempenhado pela UNESCO e o BM nesse processo. Quanto à essa política de imposição dos padrões europeus às IES da América Latina, as autoras apontam que, diferentemente do que se imagina, a Europa não compete com os EUA no que tange a Educação Superior, principalmente depois da Resolução de Bologna que tinha como objetivo uniformizar o ensino superior dos países da Europa a fim de fazer frente, como bloco, à crescente internacionalização das universidades americanas com a recepção de alunos estrangeiros. Desse modo, a Europa se apresenta como uma alternativa também para os EUA, e juntos, ambos "ditam" as regras da internacionalização segundo uma visão do Norte ou eurocentrista de mundo.

Atuando em conjunto com os sistemas de avaliação e acreditação das IES, estão os rankings acadêmicos internacionais que funcionam como uma espécie de (contra) propaganda das universidades, favorecendo (ou não) a reputação internacional das instituições. Cabe lembrar aqui o segundo mito sobre a internacionalização apresentado por Knight (2011), ou seja, de que essa reputação seja sinônimo de qualidade das IES, o que tem sido bastante difundido, impulsionando a adoção de rankings acadêmicos. Outro problema do uso desses rankings refere-se aos critérios por eles adotados, geralmente homogêneos e desenvolvidos com base nas realidades do Norte. Finardi e Guimarães (2017) analisam esses critérios e concluem que eles não apreendem aspectos inerentes aos contextos das IES brasileiras ou o aspecto local na visão de Knight (2012), prejudicando assim seu reconhecimento

12. Michael Apple (2002, p. 185, grifos nossos) ressalta que "o neoliberalismo não ignora a ideia [sic] de um Estado forte, mas quer limitá-lo a áreas específicas (por ex., defesa de mercados)". 
internacional. Mais uma vez observamos a deslegitimação e o apagamento das questões locais em função de padrões hegemônicos advindos do Norte.

Em contraposição a essas práticas, a aposta nos contextos locais se coloca como uma proposta alternativa ao processo de globalização neoliberal que tem orientado a internacionalização da educação superior. Tal empreendimento não configura, entretanto, uma política de isolamento. Pelo contrário, ela se dá através das relações de solidariedade, cooperação e democracia participativa, numa rede que enlaça o local e o global, e que, segundo nossa visão, traduz os verdadeiros benefícios e motivações da internacionalização. Assim, Sousa Santos e Avritzer (2009, p. 74) afirmam que

a globalização contra-hegemônica no domínio da ampliação e do aprofundamento da democracia depende em boa medida da ampliação e aprofundamento de redes nacionais, regionais, continentais ou globais de práticas locais.

Nesse sentido e a título de ilustração, reportamos uma parceria feita entre dois países do Sul que foi discutida durante o $1^{\circ}$ Seminário de Internacionalização do Instituto Federal da Bahia (IFBA) ${ }^{13}$, realizado em julho de 2018 nessa IES. Em uma das mesas do evento, o coordenador do projeto, o professor Alex Cypriano, descreveu uma parceria entre o Brasil, através do IFBA, e o Benim ${ }^{14}$ que tinha como objetivo fortalecer as instituições de educação profissional beninenses, visando o aumento do êxito da inserção dos egressos no mundo do trabalho, por meio do fomento às práticas de cooperativismo e agroecologia. Esse projeto tinha como objetivos específicos (1) capacitar o corpo docente do Colégio Agrícola Médji de Sékou em agroecologia e cooperativismo, (2) implantar uma incubadora de cooperativas para o apoio dos projetos cooperativistas no Colégio Agrícola Médji de Sékou e acompanhar o processo de sua consolidação e (3) monitorar e avaliar as ações desenvolvidas pelo projeto. Ainda que se esperasse uma parceria equilibrada onde todos participariam em pé de igualdade, notou-se que os beninenses esperavam que os brasileiros "ditassem" as regras e "dessem soluções" para os problemas encontrados durante o projeto, numa demonstração de dependência do modelo brasileiro, visto pelos beninenses, como sendo, naquele contexto, como o "modelo do Norte".

13. LEIRO, César; GOMES, Anilson; CYPRIANO, Alex. Experiências de internacionalização do IFBA: perspectivas futuras (Projetos Brasil-África e Brasil-Benim). Mesa redonda do I Seminário de internacionalização do IFBA, realizada em Salvador, em julho de 2018.

14. AGÊNCIA BRASILEIRA DE COOPERAÇÃO-ABC. Fortalecimento Institucional da Educação Profissional e Tecnológica do Benim nas áreas de Agroecologia e Cooperativismo. Projeto de Cooperação técnica entre Países em desenvolvimento, Bra/04/044. Brasília, 2011. $29 f$. 
É preciso, pois, que o Sul localize o Sul, e não apenas o Norte, deixando de reproduzir tais relações de dependência seja com os países do Norte ou com seus pares do Sul, como no caso mencionado acima. É urgente também compreender as complexas relações e interesses que regem a internacionalização da educação mundial, na busca por alternativas aos padrões hegemônicos e homogeneizantes, refletindo criticamente sobre as concepções de internacionalização que temos adotado. Para que essas concepções não ensejem conceitos que possam beneficiar alguns em detrimento de outros, ou ainda conceitos equivocados e mitos, segundo a visão de alguns autores (DE WIT, 2011; KNIGHT, 2011), intensificando possíveis riscos e consequências indesejáveis, é preciso desenvolver esses conceitos através da reflexão crítica, considerando os contextos e as demandas das IES, bem como as estratégias que possam orientar um processo de internacionalização ativa, conforme Lima e Maranhão (2009).

\section{METODOLOGIA}

Como apontado por Lima e Maranhão (2009), apesar da literatura estrangeira oferecer uma quantidade significativa de pesquisas na área de internacionalização da educação superior, ainda há muitas lacunas no cenário brasileiro que demandam atenção e estudo. É notório que o caso da educação profissional requer investigação urgente dada a grande expansão que esse tipo de educação teve no Brasil na última década em função da criação da Rede Federal de Educação Profissional, Científica e Tecnológica (RFEPCT), conforme relatado por Vieira et al.(2018). Além desse fator, Vieira et al. (2018) apontam a singularidade dos contextos da RFEPCT, diferentes dos das demais IES brasileiras. As autoras explicam que, assim como as universidades, a RFEPCT desenvolve atividades que contemplam a tríade ensino, pesquisa e extensão. Entretanto, a RFEPCT oferece educação pública em diferentes níveis - desde a educação básica à pós-graduação - e modalidades, com enfoque no currículo técnico e profissional. Ademais, as instituições da RFEPCT estão distribuídas por todos os estados brasileiros, com cerca de 644 unidades e campi localizados tanto em cidades urbanas quanto interioranas. A partir de uma meta-análise de estudos sobre o processo de internacionalização de universidades e da análise de dados de uma pesquisa realizada em dois institutos federais da RFEPCT, Vieira et al. (2018) percebem problemas semelhantes entre esses 
diferentes contextos, mas consideram que os desafios para os institutos federais se internacionalizarem são mais complexos que os das universidades tradicionais.

Por essas razões, o presente estudo busca preencher algumas lacunas importantes quanto à internacionalização da RFEPCT. Mais especificamente, o estudo busca trazer algumas concepções de internacionalização de sujeitos praticantes do currículo profissional da RFEPCT em diálogo com as concepções de teóricos da área. Tendo apresentado os modelos conceituais e o referencial teórico, serão apresentados, na próxima seção, as concepções de internacionalização dos sujeitos praticantes (CERTEAU, 2009) do currículo profissional da RFEPCT. Tais concepções são provenientes dos dados de um questionário semiestruturado, cujo objetivo principal era entender o que o sujeito entendia por internacionalização. Esses dados foram analisados qualitativamente em diálogo com as teorias supracitadas, e sua discussão será apresentada na Seção 4.

Os sujeitos participantes desta pesquisa são servidores da RFEPCT, lotados nas cinco regiões geográficas do país. Dadas as limitações de deslocamento físico pelo território nacional, o estudo lançou mão de questionários online. Para Creswell (2010) esses instrumentos têm possibilitado que pesquisadores criem "seus próprios levantamentos utilizando gabaritos personalizados e colocandoos em sites da web, ou os enviando por e-mail aos/às participantes para que os completem" (CRESWELL, 2010, p. 181). Os participantes deste estudo receberam o convite e o endereço eletrônico do questionário por e-mail.

Assim, o questionário semiestruturado foi divulgado e aplicado no primeiro semestre do ano de 2018, obtendo retorno de 50 respondentes que concordaram em participar da pesquisa através da leitura e assinatura digital do Termo de Consentimento Livre e Esclarecido (TCLE). Entretanto, analisamos aqui apenas as respostas completas dos concluintes do questionário, ou seja, dos 43 participantes que responderam a questão aberta "O que o(a) Sr. (a) entende por internacionalização?". Foram consideradas também as respostas parciais quanto à função desempenhada na RFEPCT, desde que atendessem aos critérios mínimos de identificação do cargo, a saber "reitor", "pró-reitor", "diretor", "coordenador", "técnico administrativo", "docente", "gestor/ assessor / secretário de Relações Internacionais" ou "outro", bem como de identificação do estado da federação desses servidores. Dos 43 participantes cujos dados serão aqui analisados, 22 deles eram docentes, 07 técnicos administrativos, 05 coordenadores, 05 gestores/ 
assessores/ secretários de Relações Internacionais, 02 diretores gerais, 01 era próreitor e 01 era aluno-estagiário ${ }^{15}$ da RFEPCT.

É importante destacar que há duas carreiras previstas na RFEPCT, a saber, a de docentes e a de técnicos administrativos. Entretanto, considerou-se relevante especificar neste estudo se esses servidores estavam desempenhando funções em cargos de confiança ou eleitos, como é o caso da nomeação de gestores, assessores ou secretários de Relações Internacionais que lidam diretamente com ações de internacionalização em suas instituições e poderiam oferecer (ou não) concepções distintas das de seus colegas de trabalho. Isso porque interessa aqui apreender os sentidos de internacionalização negociados por diferentes sujeitos praticantes do currículo profissional, a partir de seus variados lugares de fala.

Quanto às limitações e validade deste estudo, é importante destacar que mesmo dispondo de uma rede de contatos que contribuiu na divulgação do endereço eletrônico do questionário semiestruturado, tais contatos estavam mais concentrados na região Sudeste, motivo que acreditamos poder explicar o retorno mais expressivo dessa região $(74,41 \%)$, especialmente do estado do Espírito Santo. Em segundo lugar em participação neste estudo está a região Centro Oeste $(11,62 \%)$, seguida das regiões Nordeste (7\%), Norte $(4,65 \%)$ e Sul $(2,32 \%)$.

\section{A INTERNACIONALIZAÇÃO NA PERSPECTIVA DE SERVIDORES DA RFEPCT: ANÁLISE E DISCUSSÃO DAS CONCEPÇÕES DOS SUJEITOS A PARTIR DE SEUS LOCI DE ENUNCIAÇÃO}

Nesta seção será apresentada uma síntese dos dados dos questionários, com enfoque nas falas dos servidores da RFEPCT quanto às suas interpretações sobre a internacionalização, além da discussão dessas concepções. Com o intuito de evitar possíveis identificações dos sujeitos participantes deste estudo, informações como as disciplinas ministradas pelos docentes e/ou maiores detalhes sobre as funções desempenhadas pelos servidores ou suas localizações geográficas não serão dispostas na correlação de dados apresentada na tabela a seguir. Apesar de tais informações não estarem abaixo discriminadas, elas foram consideradas na análise qualitativa dos dados.

15. Dada a amplitude da Rede Federal de Educação Profissional, Científica e Tecnológica (RFEPCT), foram estipulados determinados cargos e funções como opções de respostas à pergunta de identificação do servidor/funcionário, deixando em aberto a possibilidade da resposta "outro" (cargo/função), a qual se pedia o preenchimento (opcional) da especificidade da função e/ou cargo do respondente. Consideramos interessante analisar também o sentido de internacionalização de um aluno-estagiário da RFEPCT, pois além de não estar na condição de servidor efetivo, ocupa o duplo papel de aluno e colaborador. 
Tabela 1. Respostas ao questionário

\begin{tabular}{|c|c|c|}
\hline $\begin{array}{l}\text { CARGO/ FUNÇÃO } \\
\text { NA RFEPCT }\end{array}$ & RESPONDENTE & $\begin{array}{l}\text { RESPOSTA À PERGUNTA "O QUE O(A) SR.(A) } \\
\text { ENTENDE POR INTERNACIONALIZAÇÃO?" }\end{array}$ \\
\hline \multirow[t]{9}{*}{ Docentes } & 1 & "Parceria e atividades de caráter internacional". \\
\hline & 2 & $\begin{array}{l}\text { "Troca de experiências e cooperação no âmbito } \\
\text { de ensino/pesquisa/extensão e gestão entre } \\
\text { universidades, institutos de pesquisa de países } \\
\text { distintos". }\end{array}$ \\
\hline & 3 & $\begin{array}{l}\text { "Internacionalização é o meio pelo qual as } \\
\text { instituições podem se fortalecer e trocar } \\
\text { experiências com parceiros de outros países". }\end{array}$ \\
\hline & 4 & $\begin{array}{l}\text { "Como sempre, nós mulheres negras somos } \\
\text { colocadas em segundo plano, pois toda vez que } \\
\text { se discute internacionalização tentam nos impor } \\
\text { o padrão eurocêntrico, renegando a África em } \\
\text { segundo ou terceiro plano. Fascistas!" }\end{array}$ \\
\hline & 5 & $\begin{array}{l}\text { "Envolve o intercâmbio de alunos e profissionais } \\
\text { de uma rede de ensino para outras instituições } \\
\text { de ensino de outros países do mundo, com } \\
\text { o objetivo de melhor capacitá-los do ponto } \\
\text { de vista profissional, acadêmico e científico. } \\
\text { Ao mesmo tempo, permite que alunos e } \\
\text { profissionais de outros países também venham } \\
\text { para o Brasil". }\end{array}$ \\
\hline & 6 & $\begin{array}{l}\text { "Permitir mobilidade tanto de estudantes, } \\
\text { quanto docentes e tecnologia entre diferentes } \\
\text { países". }\end{array}$ \\
\hline & 7 & "Trocas culturais entre países". \\
\hline & 8 & $\begin{array}{l}\text { "Padronizar os processos e procedimentos } \\
\text { envolvendo pesquisa, ensino e extensão aos } \\
\text { padrões internacionais, de forma a proporcional } \\
\text { intercâmbio cultural e científico". }\end{array}$ \\
\hline & 9 & $\begin{array}{l}\text { "O fato de utilizar um padrão para algumas } \\
\text { ações estabelecidas internacionalmente". }\end{array}$ \\
\hline
\end{tabular}




\begin{tabular}{|c|c|c|}
\hline \multirow[t]{9}{*}{ Docentes } & 10 & $\begin{array}{l}\text { "Troca de saberes entre diferentes países, desde } \\
\text { o ensino em mais de uma língua, passando pela } \\
\text { publicação em diferentes línguas e países, bem } \\
\text { como o intercâmbio de docentes e discentes". }\end{array}$ \\
\hline & 11 & $\begin{array}{l}\text { "Pretendo que os alunos tenham condição de } \\
\text { buscar referências na literatura internacional, } \\
\text { bem como me preparar para as aulas com mais } \\
\text { informações". }\end{array}$ \\
\hline & 12 & $\begin{array}{l}\text { "Inserção internacional da escola por meio } \\
\text { de ensino ou pesquisa, com participação } \\
\text { em eventos internacionais e organização, } \\
\text { intercâmbio de discentes e docentes". }\end{array}$ \\
\hline & 13 & $\begin{array}{l}\text { "Possibilidade de recebermos alunos de fora do } \\
\text { país e também de levar nossos alunos para fora". }\end{array}$ \\
\hline & 14 & $\begin{array}{l}\text { "Intercâmbio cultural, trocas de experiências } \\
\text { exitosas na área, entre nossa instituição e outras } \\
\text { no exterior". }\end{array}$ \\
\hline & 15 & "Nada, a princípio". \\
\hline & 16 & $\begin{array}{l}\text { "São atitudes para fomentar a difusão do } \\
\text { conhecimento técnico e científico de um local a } \\
\text { níveis globais (internacionais)". }\end{array}$ \\
\hline & 17 & $\begin{array}{l}\text { "De maneira simplificada compreendo } \\
\text { internacionalização como um processo } \\
\text { demandado pelo século XXI e que passa a } \\
\text { permear todos os âmbitos institucionais como } \\
\text { o ensino, a pesquisa e a extensão. Em outras } \\
\text { palavras, podemos utilizar a metáfora do guarda- } \\
\text { chuva para nos referir a internacionalização, no } \\
\text { sentido de que ela é meio e não fim. Isto é, a } \\
\text { internacionalização amarra as outras áreas de } \\
\text { trabalho a fim de estimular o desenvolvimento } \\
\text { institucional e acelerar processo, os quais sem } \\
\text { ela necessitariam de mais tempo para fornecer } \\
\text { resultados satisfatórios". }\end{array}$ \\
\hline & 18 & $\begin{array}{l}\text { "Trocas econômicas, políticas e culturais entre } \\
\text { nações e, no campo da educação, trocas de } \\
\text { conhecimentos". }\end{array}$ \\
\hline
\end{tabular}




\begin{tabular}{|c|c|c|}
\hline \multirow[t]{4}{*}{ Docentes } & 19 & $\begin{array}{l}\text { "Internacionalização é o processo que permite } \\
\text { compartilhamento de informações, modelos } \\
\text { de gestão e formas de fazer a educação entre } \\
\text { diversos países. É uma importante estratégia } \\
\text { para inserir nossas instituições no cenário } \\
\text { global". }\end{array}$ \\
\hline & 20 & $\begin{array}{l}\text { "Entendo por poder compartilhar não apenas } \\
\text { conhecimentos científicos, mas também } \\
\text { questões sociais, culturais, com outros } \\
\text { sociedades e aprender com elas valores } \\
\text { diferentes, mas nem por isso menores ou } \\
\text { maiores que os nossos. Entendo também, como } \\
\text { um processo inevitável para que os nossos } \\
\text { cursos possam progredir". }\end{array}$ \\
\hline & 21 & $\begin{array}{l}\text { "Incorporação de valores ou ideias de uns com } \\
\text { relação a outros". }\end{array}$ \\
\hline & 22 & $\begin{array}{l}\text { "Seria a troca de informações e serviços além do } \\
\text { âmbito local envolvendo âmbito externo". }\end{array}$ \\
\hline \multirow[t]{7}{*}{$\begin{array}{l}\text { Técnicos } \\
\text { Administrativos }\end{array}$} & 23 & $\begin{array}{l}\text { "Seria a projeção do instituto, de suas atividades } \\
\text { e profissionais para outros países, uma espécie } \\
\text { de intercâmbio com instituições de educação". }\end{array}$ \\
\hline & 24 & $\begin{array}{l}\text { "Uma forma de envolver culturas e } \\
\text { conhecimentos, de forma a elevar saberes e } \\
\text { difundir paradigmas". }\end{array}$ \\
\hline & 25 & $\begin{array}{l}\text { "Oportunidade de ensino ou trabalho } \\
\text { que poderá ser desenvolvido integral ou } \\
\text { parcialmente em outro país, auxiliando assim no } \\
\text { desenvolvimento profissionalizante e de novas } \\
\text { línguas estrangeiras". }\end{array}$ \\
\hline & 26 & "Expansão para outros países". \\
\hline & 27 & $\begin{array}{l}\text { "Estabelecer parcerias com pesquisadores } \\
\text { e instituições de ensino de outros países, } \\
\text { promover eventos internacionais e publicações } \\
\text { socializando a pesquisa e produção entre países". }\end{array}$ \\
\hline & 28 & $\begin{array}{l}\text { "Intercâmbio entre profissionais, pesquisa } \\
\text { conjunta e produção de novos conhecimentos". }\end{array}$ \\
\hline & 29 & $\begin{array}{l}\text { "É o estabelecimento de relações com outros } \\
\text { países". }\end{array}$ \\
\hline
\end{tabular}




\begin{tabular}{|c|c|c|}
\hline \multirow[t]{5}{*}{ Coordenadores } & 30 & $\begin{array}{l}\text { "Internacionalização se refere a troca de } \\
\text { informações entre países". }\end{array}$ \\
\hline & 31 & $\begin{array}{l}\text { "Fazer com que o currículo do curso seja } \\
\text { pensado em caráter global". }\end{array}$ \\
\hline & 32 & $\begin{array}{l}\text { "Ir além das fronteiras de um país. Relacionar-se } \\
\text { com outros países". }\end{array}$ \\
\hline & 33 & $\begin{array}{l}\text { "Integração de algo entre países, ou seja, tarefas, } \\
\text { atividades, conteúdos que serão os mesmos } \\
\text { nos países que optam em internacionalizar. } \\
\text { Por exemplo, internacionalização da } \\
\text { contabilidade do setor público, é praticamente } \\
\text { a mesma em diversos países (ainda em fase de } \\
\text { implementação)". }\end{array}$ \\
\hline & 34 & $\begin{array}{l}\text { "Processo no qual se integra uma dimensão } \\
\text { internacional, intercultural ou global na } \\
\text { educação". }\end{array}$ \\
\hline \multirow{5}{*}{$\begin{array}{l}\text { Gestores/ } \\
\text { Assessores/ } \\
\text { Secretários } \\
\text { de Relações } \\
\text { Internacionais }\end{array}$} & 35 & $\begin{array}{l}\text { "Um processo crítico de abertura da IES ao } \\
\text { ambiente internacional". }\end{array}$ \\
\hline & 36 & $\begin{array}{l}\text { "É o relacionamento entre diferentes povos, } \\
\text { países e culturas". }\end{array}$ \\
\hline & 37 & $\begin{array}{l}\text { "Processo que envolve eixos caros às políticas } \\
\text { de relações internacionais, com vistas a } \\
\text { transformar, por meio da mobilidade, parcerias, } \\
\text { políticas linguísticas, cultura, ecossistemas de } \\
\text { inovação, políticas de fronteiras, todas a relações } \\
\text { institucionais, de forma transversal às dimensões } \\
\text { de Ensino, de Pesquisa e Inovação, e de Extensão". }\end{array}$ \\
\hline & 38 & $\begin{array}{l}\text { "Processo de acesso a outras línguas, culturas } \\
\text { e conhecimento, por meio do contato com } \\
\text { estrangeiros em seu país ou por meio da } \\
\text { mobilidade internacional, seja no âmbito } \\
\text { acadêmico, pessoal ou profissional". }\end{array}$ \\
\hline & 39 & $\begin{array}{l}\text { "Processo de estreitamento de relações } \\
\text { interinstitucionais no âmbito internacional, nas } \\
\text { diversas áreas de atuação, como: economia, } \\
\text { gestão, saúde, educação, entre outros, com } \\
\text { vistas ao compartilhamento de ideias e } \\
\text { experiências para construção de conhecimentos } \\
\text { e soluções de problemas de efeito local, porém, } \\
\text { de ordem mundial". }\end{array}$ \\
\hline
\end{tabular}




\begin{tabular}{|c|c|c|}
\hline \multirow[t]{2}{*}{ Diretores Gerais } & 40 & $\begin{array}{l}\text { "Trata-se de um intercâmbio de produtos, } \\
\text { serviços, idéias [sic] e cultura entre diferentes } \\
\text { países". }\end{array}$ \\
\hline & 41 & $\begin{array}{l}\text { "Internacionalização é uma ação que visa } \\
\text { integrar currículos em relação ao idioma, } \\
\text { cultura, projetos e procedimentos comuns } \\
\text { para a troca e o compartilhamento de saberes e } \\
\text { experiências acadêmicas e institucionais". }\end{array}$ \\
\hline $\begin{array}{l}\text { Pró-Reitor de } \\
\text { Pesquisa e Pós- } \\
\text { Graduação }\end{array}$ & 42 & $\begin{array}{l}\text { "Estruturar a instituição para que seus diversos } \\
\text { setores estejam aptos a desenvolver suas } \\
\text { atividades normais na recepção de estrangeiros } \\
\text { ou para a saída para o exterior de membros da } \\
\text { comunidade". }\end{array}$ \\
\hline Aluno/ Estagiário & 43 & $\begin{array}{l}\text { "Na minha opinião é o ato de tornar algo } \\
\text { internacional ou atuar em âmbito internacional; } \\
\text { realizar ações de cultura internacional". }\end{array}$ \\
\hline
\end{tabular}

Fonte: Das autoras

A análise qualitativa dos dados do questionário demonstrou muitas aproximações das concepções dos sujeitos praticantes do currículo profissional com as discussões propostas por teóricos da área de internacionalização. Algumas dessas perspectivas manifestam a postura crítica que os sujeitos estão adotando com relação à internacionalização da educação, porém outras ainda enfatizam aspectos dos conceitos equivocados e mitos mais comuns apontados por de Wit (2011) e Knight (2011). Apesar de apresentarem diálogo com esses mitos e equívocos, algumas dessas concepções também conversam com o modelo teórico de Knight (2003), o que pode indicar um movimento de transição epistemológica de um conceito equivocado/mito (conforme DE WIT, 2011; e KNIGHT, 2011) para uma perspectiva mais reflexiva.

Com relação a esses conceitos que podem induzir a certos riscos e consequências indesejáveis para as IES, podemos destacar as aproximações com os seguintes conceitos de internacionalização identificados por de Wit (2011) como sendo equivocados: estudar ou morar em um país estrangeiro (respondentes 05, 06, $13,25,38$ e 42); quanto maior a quantidade de parcerias, mais internacionalizada é a instituição (respondentes 01, 27 e 28); e ter alunos estrangeiros matriculados na instituição (respondentes 05, 06, 13 e 42). Esse último se aproxima também do mito mencionado por Knight (2011) de que estudantes estrangeiros seriam agentes da internacionalização. 
É importante citar, ainda, que algumas concepções dialogam com outro mito acerca da internacionalização apontado por Knight (2011), o de que quanto maior o reconhecimento de qualidade conferido por agências e órgãos internacionais, mais internacionalizada é a instituição (a exemplo do respondente 08 ) $^{16}$. Nesse sentido, a adoção de termos que indicam a padronização de currículos, procedimentos, avaliações e rankings (respondentes 08, 09, 33 e 41) também se relaciona com esse último mito.

Com base nos estudos que assinalam os riscos de homogeneização das IES (KNIGHT, 2012; LEITE; GENRO, 2012; FINARDI; GUIMARÃES, 2017) percebe-se nos sentidos de internacionalização produzidos pelos respondentes 33 e 41 certa semelhança conceitual entre "integração" e "padronização". Tal percepção aponta um questionamento, para futuras pesquisas: integrar atividades, procedimentos e/ou currículos significa padronizá-los (homogeneizá-los) entre as IES?

Outro problema assinalado por de Wit (2011) e Knight (2011) refere-se à visão de internacionalização enquanto "atividades" que possam ter algum teor internacional. $\mathrm{Na}$ análise dos dados do questionário, se percebe que dois conceitos produzidos por docentes (respondentes 01 e 22), bem como as concepções do pró-reitor e do aluno-estagiário guardam aproximações com essa visão: o emprego dos termos "atividades", "serviços" e "ações" parece se aproximar desse sentido.

É notório também o uso de expressões como "relações" ou "relacionamentos" entre países e culturas (a exemplo dos respondentes 29, 32 e 36). De modo semelhante, termos como "trocas", "compartilhamento" ou "intercâmbio" de "conhecimentos", "culturas" e "experiências" são bastante frequentes, sendo utilizados por cerca de $41 \%$ dos docentes, $14 \%$ dos técnicos administrativos, $20 \%$ dos coordenadores e gestores/ assessores/ secretários de Relações Internacionais, e por todos os diretores gerais participantes deste estudo. Ainda que esses últimos termos possam remeter a ideia de democratização do conhecimento, nem todos os usos analisados expressam esse viés crítico.

Apesar disso, muitos dos sujeitos praticantes do currículo profissional demonstram negociar sentidos de internacionalização com as concepções de cunho mais crítico mencionadas na Seção 2.2. Dentre esses sentidos analisados, destacamos os que compreendem a internacionalização como forma de democratizar/ difundir/ produzir/ construir conhecimentos (respondentes 10,11, 16, 21, 24, 27, 28 e 39).

16. Ainda que não mencionem quaisquer tipos de avaliações de agências internacionais, os respondentes 12, 19 e 23 fazem alusão à suposta importância do reconhecimento internacional da IES ao utilizarem termos como "inserção" e "projeção" da instituição. 
Outro destaque diz respeito à compreensão da internacionalização da educação conforme o modelo conceitual de Knight $(2003$; 2004), percebida, em especial, nas concepções dos respondentes $02,17,34,37$ e 39. Observa-se, também, nessas concepções a ênfase de internacionalização enquanto processo (KNIGHT, 2003) e não um fim em si mesmo (DE WIT, 2011; KNIGHT, 2012).

Por fim, merecem destaque também os sentidos propostos criticamente pelos respondentes $04,16,20,35$ e 37, especialmente as concepções dos docentes que refletem sobre as relações entre o local e o global (respondente 16) e sobre a necessidade de se descolonizar o processo de internacionalização das IES do Sul (respondente 04), questões caras para este estudo. Ainda que o respondente 16 faça uso da expressão "atitudes", sua interpretação de internacionalização traz a emergência dos saberes produzidos localmente a serem difundidos/democratizados mundialmente. Quanto à concepção descolonizadora, o primeiro ponto a se salientar é que a respondente 04 fora a única dentre os 43 participantes analisados que se identificou como mulher, descolonizando, primeiramente, a linguagem (MORENO, 1999) através do uso do gênero feminino ("colocadas"). Em seguida, a docente enfatiza seu lugar de fala como "mulher negra" e traz a questão do eurocentrismo e do racismo e fascismo ("Fascistas!") em relação à África: "[...] toda vez que se discute internacionalização tentam nos impor o padrão eurocêntrico, renegando a África em segundo ou terceiro plano [...]".

Os sujeitos praticantes (CERTEAU, 2009) do currículo criam estratégias para resistir e (re) existir. Essa última participante se utilizou do espaço oportunizado por esta pesquisa para se fazer ouvida, e esperamos que sua voz, bem como as dos demais sujeitos participantes deste estudo repercutam para além das fronteiras deste texto.

\section{CONSIDERAÇÕES FINAIS}

A presente pesquisa buscou investigar as concepções de internacionalização da educação superior dos sujeitos praticantes (CERTEAU, 2009) do currículo profissional, os servidores da Rede Federal de Educação Profissional, Científica e Tecnológica (RFEPCT), em diálogo com a literatura da área. Com esse objetivo, um questionário semiestruturado foi aplicado a servidores lotados nas cinco regiões geográficas do Brasil, obtendo o retorno de 43 respondentes, sendo a maioria deles localizada na região Sudeste. O estudo contou também com uma revisão de literatura acerca do conceito investigado, a fim de traçar possíveis diálogos entre 
os modelos conceituais e a discussão proposta por teóricos da área e os sentidos de internacionalização produzidos pelos sujeitos participantes.

De modo geral, a análise qualitativa dos dados do questionário demonstra que muitas das concepções dos servidores da RFEPCT se aproximam dos "conceitos equivocados" e dos "mitos" sobre a internacionalização apontados por de Wit (2011) e Knight (2011), apesar de algumas delas expressarem certo movimento de transição epistemológica em direção à uma conceitualização mais próxima do modelo de Knight (2003).

Outras concepções, entretanto, apresentaram um viés mais crítico quanto às posturas que esses sujeitos praticantes do currículo profissional adotam em relação ao currículo, expressando o desejo de enfatizar as questões locais nas relações com o global, bem como por descolonizar o processo de internacionalização das IES do Sul.

Por fim, ressaltamos que este trabalho não tem como objetivo esgotar o diálogo entre os conceitos de internacionalização trazidos pelos dados deste estudo e os teóricos da área. Muito pelo contrário, pretendemos dar um passo em direção ao diálogo e a uma melhor compreensão do conceito de internacionalização em contextos locais em diálogo com a literatura global e local. Nesse sentido, este artigo representa uma contribuição local para esse diálogo, que está apenas iniciando.

\section{$\overline{\text { REFERÊNCIAS }}$}

ALTBACH, P. G. (2016). Global perspectives on bigher education. JHU Press.

ALTBACH, P. G.; KNIGHT, J. (2007). The internationalization of bigher education: Motivations and realities. Journal of studies in international education. v. 11, $\mathrm{n}^{\circ}$ 3-4, pp. 290-305.

AMORIM, G. B.; FINARDI, K. R. (2017). Globalização e internacionalização do ensino superior: Evidências de um estudo de caso nos níveis micro, meso e macro. Avaliação: Revista da Avaliação da Educação Superior. v. 22, nº 3 pp. 614-632.

ANDREOTTI, V. O.; PEREIRA, R.S.; EDMUNDO, E. S. G.; ARAÚJO, F.. (2016). Internacionalização da educação brasileira: possibilidades, paradoxos e desafios. In: LUNA, J. M. F. (org.). Internacionalização do currículo: educação, interculturalidade, cidadania global. Campinas: Pontes Editores, pp. 129-154.

APPLE, M. W. (2002) O que os pós-modernistas esquecem: capital cultural e conhecimento oficial. In: GENTILI, P. A. A.; SILVA, T. T. (orgs.). Neoliberalismo, qualidade total e educação: visões críticas, $11^{\mathrm{a}}$ Ed. Petrópolis: Editora Vozes, pp. 179-204. 
AZEVEDO, M. L. N. (2014). A internacionalização da Educação Superior em questão: mitos, enganos e verdades. Horizontes LatinoAmericanos - Revista de Humanidades e Ciências Sociais do Mercosul Educacional. v. 3, nº 1, pp. 99-110.

CERTEAU, M. (2009). A invenção do cotidiano: artes de fazer. $16^{\mathrm{a}}$ Ed. Petrópolis: Vozes.

CRESWELL, J. W. (2010). Projeto de pesquisa: métodos qualitativo, quantitativo e misto. $3^{\text {a }}$ Ed. Porto Alegre: Artmed, pp. $177-265$

DE WIT, H. (2011). Internationalization of Higher Education: nine misconceptions. International Higher Education. $n^{\circ}$ 64, pp. 1-6.

FERRAÇO, C. E. (2013). Currículos, culturas e cotidianos escolares: afirmando a complexidade e a diferença nas redes de conhecimentos dos sujeitos praticantes. Leitura: Teoria \& Prática. v. 31, nº 60, pp. 81-103.

FINARDI, K. R.; ARCHANJO, R. (2018). Washback Effects of the Science Without Borders, English Without Borders and Language Without Borders Programs in Brazilian Language Policies and Rights. In: SIINER, M.; HULT, F.; KUPISCH, T. (orgs.). Language Policy and Language Acquisition Planning. Language Policy, $1^{\mathrm{a}} \mathrm{Ed}$. Cham: Springer, v. 15, pp. 173-185.

FINARDI, K. R.; FRANÇA, C. (2016). O Inglês na Internacionalização da Produção Científica Brasileira: Evidências da Subárea de Linguagem e Linguística. Intersecções (Jundiaí). v. 19, n 2, pp. 234-250.

FINARDI, K.; GUIMARÃES, F. F. (2017). Internacionalização, rankings e publicações em inglês: a situação do Brasil na atualidade. Estudos em Avaliação Educacional. v. 28, no 68, pp. 600-626.

FINARDI, K. R.; SANTOS, J. M.; GUIMARÃES, F. (2016). A Relação entre Línguas Estrangeiras e o Processo de Internacionalização: Evidências da Coordenação de Letramento Internacional de uma Universidade Federal. Interfaces Brasil/Canadá, Revista Brasileira de Estudos Canadenses. v. 16, nº 1, pp. 233-255.

FORTES, R. (2016). Política científica no Brasil: dilemas em torno da internacionalização e do inglês. Interfaces Brasil/Canadá, Revista Brasileira de Estudos Canadenses. v. 16, nº 1, pp. 151-190.

FREIRE, P. (1970). Pedagogia do oprimido. Rio de Janeiro: Zahar. 
KNIGHT, J. (2012). Cinco verdades sobre internacionalização. In: International Higher Education, v. 69: outono (Hemisfério Norte). Edição brasileira mediante acordo de cooperação entre UNICAMP e Boston College - Revista Ensino Superior Unicamp. Campinas: Unicamp, pp. 64-66.

KNIGHT, J. (2011). Five myths about internationalization. International Higher Education. ${ }^{\circ}$ 62, pp. $14-15$.

KNIGHT, J. (2004). Internationalization remodeled: definition, approaches, and rationales. Journal of studies in international education. v. $8, \mathrm{n}^{\circ} 1$, pp. 5-31.

KNIGHT, J. (2003). Updating the definition of internationalization. International Higher Education. v. $33, \mathrm{n}^{\circ} 6$, pp. 2-3.

KNIGHT, J. (1994). Internationalization: Elements and Checkpoints. CBIE Research Canadian Bureau for International Education (CBIE)/Burean canadien de l'éducation internationale (BCEI). no 7, pp. 1-14.

LAUS, S. P. (2012). A internacionalização da educação superior: um estudo de caso da Universidade Federal de Santa Catarina. Tese de Doutorado em Administração. Escola de Administração, Universidade Federal da Bahia, Salvador.

LEITE, D.; GENRO, M. E. H. (2012). Avaliação e internacionalização da Educação Superior: Quo vadis América Latina? Avaliação: Revista da Avaliação da Educação Superior. v. $17, \mathrm{n}^{\circ} 3$, pp. $763-785$.

LIMA, M. C.; MARANHÃO, C. M. S. A. (2009). O sistema de educação superior mundial: entre a internacionalização ativa e passiva. Avaliação. v. 14, nº 3, pp. 583-610.

MORENO, M. (1999). Como se ensina a ser menina: o sexismo na escola. São Paulo: Moderna.

OLIVEIRA, P. S. (2018). Internacionalização da educação superior: um estudo de caso em instituições públicas de ensino superior do estado da Babia. Dissertação de Mestrado em Educação. Programa de Pós Graduação em Educação, Universidade Federal da Bahia, Salvador.

SACRISTÁN, J. G. (1995). Currículo e diversidade cultural. In: SILVA, T. T.; MOREIRA, A. F. B. (orgs.). Territórios contestados: o currículo e os novos mapas políticos e culturais. Petrópolis: Vozes, pp. 82-113.

SEMERARO, G. (2012). Da Libertação à Hegemonia: Freire e Gramsci no processo de democratização do Brasil In: BERND FICHTNER, E. F.; FORESTE, G. M. S.; 
LIMA, M. (orgs.). Cultura, Dialética e Hegemonia: Pesquisas em Educação. Vitória: EDUFES, pp. $23-44$.

SOUSA SANTOS, B.; AVRITZER, L. (2009). Para ampliar o cânone democrático. In: SANTOS, B. S. (org.). Democratizar a democracia: os caminhos da democracia participativa. $4^{\text {a }}$ Ed. Rio de Janeiro: Civilização Brasileira.

SOUSA SANTOS, B. (2011). A universidade no século XXI: para uma reforma democrática e emancipatória da universidade. $3^{\mathrm{a}}$ Ed. São Paulo: Cortez.

VAVRUS, F.; PEKOL, A. (2015). Critical Internationalization: Moving from theory to Practice. FIRE: Forum for International Research in Education. v. 2, n 2, pp. 5-21.

VIEIRA, G. V.; FINARDI, K. R.; PICCIN, G. F. O. (2018). Going international: the challenges for Brazilian Federal Institutes of Education, Science and Technology. Revista Ibero-Americana de Estudos em Educação. v. 13, n. esp 1, pp. 394-410.

Recebido: 30/08/2018

Aceito: 18/12/2018

Publicado: 29/03/2019 